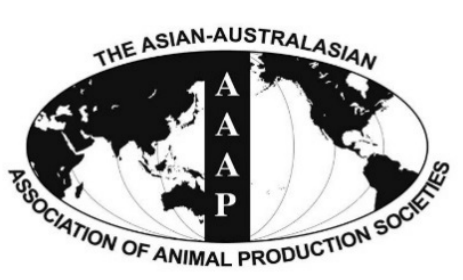

Open Access

Asian Australas. J. Anim. Sci.

Vol. 28, No. 12 : 1721-1728 December 2015

http://dx.doi.org/10.5713/ajas.15.0497

www.ajas.info

pISSN 1011-2367 elSSN 1976-5517

\title{
Characterization of Bovine NANOG5'-flanking Region during Differentiation of Mouse Embryonic Stem Cells
}

\author{
Hye-Jeong Jang, Hwan Hee Park, Tran Thi Thuy Linh, Hak-Kyo Lee ${ }^{1}$, Ki-Duk Song ${ }^{1, *}$, and Woon Kyu Lee* \\ Laboratory of Developmental Genetics, Department of Biomedical Sciences, \\ Inha University School of Medicine, Incheon 400-712, Korea
}

\begin{abstract}
Embryonic stem cells (ESCs) have been used as a powerful tool for research including gene manipulated animal models and the study of developmental gene regulation. Among the critical regulatory factors that maintain the pluripotency and self-renewal of undifferentiated ESCs, NANOG plays a very important role. Nevertheless, because pluripotency maintaining factors and specific markers for livestock ESCs have not yet been probed, few studies of the NANOG gene from domestic animals including bovine have been reported. Therefore, we chose mouse ESCs in order to understand and compare NANOG expression between bovine, human, and mouse during ESCs differentiation. We cloned a 600 bp $(-420 /+181)$ bovine NANOG 5 '-flanking region, and tagged it with humanized recombinant green fluorescent protein (hrGFP) as a tracing reporter. Very high GFP expression for bovine NANOG promoter was observed in the mouse ESC line. GFP expression was monitored upon ESC differentiation and was gradually reduced along with differentiation toward neurons and adipocyte cells. Activity of bovine NANOG $(-420 /+181)$ promoter was compared with already known mouse and human NANOG promoters in mouse ESC and they were likely to show a similar pattern of regulation. In conclusion, bovine NANOG 5-flanking region functions in mouse ES cells and has characteristics similar to those of mouse and human. These results suggest that bovine gene function studied in mouse ES cells should be evaluated and extrapolated for application to characterization of bovine ES cells. (Key Words: Bovine, Embryonic Stem Cell, NANOG, Promoter, Neural Differentiation, Adipocyte Differentiation)
\end{abstract}

\section{INTRODUCTION}

Zygote and morula stage embryos possess a totipotency for generation of a whole organism. Only cells of the inner cell mass (ICM) from blastocyst have the pluripotent capacity for formation of all three primary germ layers, endoderm, mesoderm, and ectoderm. In adult tissues, multipotent stem and progenitor cells exist in tissues and organs for replacement of lost or injured cells (Wobus and Boheler, 2005). Embryonic stem cells (ESCs) are derived from the ICM in the blastocyst stage embryo and can rise to all cells of the embryo (Suda et al., 1987). Once established

\footnotetext{
* Corresponding Authors: Ki-Duk Song. Tel: +82-63-270-4748, Fax: +82-63-270-2614, E-mail: kiduk.song@gmail.com / Woon Kyu Lee. Tel: +82-32-890-0946, Fax: +82-32-890-1199, E-mail: wklee@inha.ac.kr

1 Department of Animal Biotechnology, Chonbuk National University, Jeonju 561-756, Korea.

Submitted Jun. 8, 2015; Revised Jul. 25, 2015; Accepted Aug. 12, 2015
}

in vitro, ESCs can be cultured indefinitely without losing their pluripotency, and have the capacity to develop into any cell type in the body, and self-renewal (Okita and Yamanaka, 2006). In addition, development of undifferentiated ESCs occurs in vitro via three-dimensional aggregates (embryoid body [EB]) into differentiated cell types of all three primary germ layers (Kim et al., 2009).

The capacity for self-renewal and the pluripotency of ESCs is known to be controlled by the transcription factors, Nanog homeobox (NANOG), octamer binding transcription factor-4 (OCT4) and sex determining region-Y box-2 (SOX2), and signaling pathways like leukemia inhibitory factor (LIF)-signal transducer and activator of transcription 3 (STAT3) and bone morphogenic protein (BMP)-Mothers against decapentaplegic homolog (SMAD) 1/4/5/8 (Rodda et al., 2005). Function and capability of these transcriptional genes and signaling pathways depend on the stage of development of the self-renewal and pluripotent cells, indicating that these factors function in combination with 
other processes (Chickarmane et al., 2006). These transcription factors activate repressed pattern of gene expression like GATA binding transcription factor $4 / 6$ (GATA4/6) and caudal type homeobox 2 (CDX), which mediate phenotypic changes toward endoderm during stem cell differentiation, and repress activated pattern of gene expression for differentiation to mesoderm and ectoderm like T-box transcription factor 3 (TBX3) and estrogenrelated receptor beta (ESRRB) (Boyer et al., 2005).

Among ESCs transcription factors, NANOG is a homeobox-containing a transcription factor with an essential role in maintaining the pluripotent cells of the ICM and ESCs (Liu et al., 2007). It is expressed in pluripotent cells and is absent from differentiated cells. Both NANOG and OCT4 promoter-driven enhanced green fluorescent protein (EGFP) have been monitored in undifferentiated state ESCs, but not detected following differentiation (Gerrard et al., 2005). Disruption of NANOG in ESCs results in differentiation to endoderm lineages (Hamazaki et al., 2004), while over-expression of NANOG in mouse ESCs renders LIF dependent ESCs self-renewal, although the self-renewal capacity of the cells is reduced, suggesting that NANOG is a major regulator of the pluripotent state. The NANOG over-expression effect is neither dependent on STAT3 activation nor requires presence of BMP4 (Liu et al., 2007). However, little is known about regulation of NANOG gene expression with various transcriptional regulators.

So far, validated ESC lines that can contribute to the germline in chimeras have only been established in mice, rats, and chickens (Pain et al., 1996; Buehr et al., 2008; Li et al., 2008). While ESC lines have also been established in other species, they have not been fully validated due to either ethical reasons in the case of human (Thomson et al., 1998) or technical reasons in the case of mink (Sukoyan et al., 1993), hamster (Doetschman et al., 1988), rhesus monkey (Thompson et al., 1995), canine (Hatoya et al., 2006; Hayes et al., 2008), and various large domestic species. Bovine induced pluripotent stem cells (iPSCs) and ESC-like cells have been established, but not maintained long-term (Keefer et al., 2001; Huang et al., 2011; Sumer et al., 2011). For these reasons, the molecular characteristics of NANOG from domestic animals including bovine have not yet been fully determined. The bovine NANOG promoter sequences $(-420 /+181)$ were isolated and their promoter activity was examined in mouse ESCs as a heterologous system. In transfection study, the bovine NANOG promoter exhibited strong activity in mouse ESCs as a heterologous system and its promoter activity was down-regulated during ESCs differentiation, suggesting that NANOG promoter activity is conserved across the mammalian species and bovine $N A N O G$ promoter will be useful in development of bovine ESCs.

\section{MATERIALS AND METHODS}

\section{Isolation of bovine NANOG 5'-flanking region and construction of bovine NANOG promoter-green fluorescent protein reporter recombinant plasmid}

Bovine genomic DNA was isolated from ear cells of Korean beef cattle using the Wizard Genomic DNA purification kit (Promega, Madison, WI, USA). The bovine NANOG promoter region was amplified from the $+181 \mathrm{bp}$ region (anti-sense primer: 5'-CTGCTTGCTCACCAT GTTGCTGAGTTGAAGGAG-3') to the -420 bp region (sense primer: 5'-CCGGAAGCTTAAAGAGGAAAAT GGAGTTAG-3'). Polymerase chain reaction (PCR) amplification was performed using $10 \mathrm{ng}$ of genomic DNA template in final volumes of $50 \mu \mathrm{L}$ using AccuPower Pfu PCR PreMix (Bioneer, Daejeon, Korea). The PCR conditions were as follows: $94^{\circ} \mathrm{C}$ for $5 \mathrm{~min}$, followed by 35 cycles of denaturation at $94^{\circ} \mathrm{C}$ for $30 \mathrm{~s}$, annealing at $64^{\circ} \mathrm{C}$ for $45 \mathrm{~s}$, extension at $72^{\circ} \mathrm{C}$ for $1 \mathrm{~min}$, and the final extension step was prolonged to $5 \mathrm{~min}$. The PCR product was digested with HindIII (TAKARA, Shiga, Japan) and sticky/blunt ligated into the EcoRV and HindIII site of phrGFP II-C (Agilent Technologies Genomics, Santa Clara, CA, USA) using a ligase kit (ELPIS, Daejeon, Korea).

\section{Cell culture and transgenic cell line}

Mouse ESC lines (R1) were cultured on inactivated mouse primary embryonic fibroblast feeder cells with mitomycin C (Sigma, St. Louis, MO, USA) and grown in Dulbecco's Modified Eagle's Medium (DMEM) (Gibco, USA), $15 \%$ fetal calf serum (HyClone, Logan, UT, USA), $0.1 \mathrm{mM}$ 2-mercaptoethanol (Gibco, USA), $1 \%$ non-essential amino acids (Gibco, USA), $2 \mathrm{mM}$ L-glutamine (Gibco, USA), $1 \mathrm{mM}$ MEM sodium pyruvate solution (Gibco, USA), $1 \%$ penicillin/streptomycin (Gibco, USA), and 1,000 U/mL LIF (ES-GRO, Chemicon, Billerica, MA, USA). Cells were maintained at $37^{\circ} \mathrm{C}$ with $5 \% \mathrm{CO}_{2}$. Recombinant plasmids of mouse NANOG $(-332 /+50)$ and human NANOG $(-380 /+24)$ tagged with pEGFP-N1 as an expression reporter were generously donated by Dr. Takashi Tada, Laboratory of Stem Cell Engineering at Kyoto University (Kyoto, Japan). Mouse, human, and bovine NANOG promoter-GFP reporter vectors were linearized, and each $4.7 \mathrm{~kb}, 4.5 \mathrm{~kb}$, and $4.6 \mathrm{~kb}$ transgene was electroporated into $1 \times 10^{7} \mathrm{R} 1$ cells at $1,400 \mathrm{~V}, 10 \mathrm{~ms}$, and pulse number 3 using a Neon Transfection System (Life Technologies, Grand Island, NY, USA). After positive selection with G418 (Sigma, USA) for 1 week, integration of the transgenes in the genome of ESC was assessed by fluorescence with an FITC filter.

\section{Neural differentiation}

For differentiation, mouse embryonic fibroblasts (MEF) 
from ESC culture were removed using $0.1 \%$ gelatin coated $10 \mathrm{~cm}$ petri dishes. MEF free ESCs were cultured in aggregated EBs. Mouse ESCs were cultured in EB formation medium in the absence of LIF in a non-adhesive $10 \mathrm{~cm}$ petri dish for 4 days by suspension of $2 \sim 3 \times 10^{6} \mathrm{MEF}$ free ESCs. More directed differentiation of ESCs to the neuronal lineage occurred upon addition of $0.5 \mu \mathrm{M}$ alltrans-retinoic acid (RA, Millipore, Billerica, MA, USA) to the culture for an additional 4 days. Neural induced EBs were subsequently transferred to poly-L-ornithine (10 $\mathrm{mg} / \mathrm{mL}$, Millipore, USA) and laminin ( $1 \mathrm{mg} / \mathrm{mL}$, Millipore, USA) coated slides and cultured in EB formation medium for an additional 8 days. Medium was changed every two days.

\section{Adipocyte differentiation}

MEF free mouse ESCs were cultured in EB formation medium in a non-adhesive $10 \mathrm{~cm}$ petri dish for 2 days in the absence of LIF to help in formation of EBs. More directed differentiation of ESCs to the adipocyte lineage occurred upon the addition of $0.1 \mu \mathrm{M}$ RA to the culture for an additional 3 days. Induced EBs were subsequently transferred to $0.1 \%$ gelatin coated wells and cultured in freshly prepared adipocyte differentiation medium including $20 \mathrm{nM} \mathrm{3,} \mathrm{3',} \mathrm{5-triiodo-L-thyronine} \mathrm{(T3)} \mathrm{solution}$ and $850 \mathrm{nM}$ insulin solution (Millipore, USA) in the EB formation medium for an additional 21 days. Medium was changed every two days.

\section{Immunofluorescence staining}

Monolayer cultures of differentiated cells were rinsed with phosphate-buffered saline (PBS) and incubated for 10 min at room temperature in PBS ( $\mathrm{pH} 7.4)$ containing 4\% paraformaldehyde. After each of three rinses with PBS and $5 \%$ normal donkey serum (Abcam, Cambridge, MA, USA) in PBS, the cells were blocked for $2 \mathrm{~h}$ at room temperature with PBS containing 5\% donkey serum and $0.3 \%$ Triton X100. The cells were then incubated with mouse NESTIN (1:200), mouse C/EBP $\beta$ (1:100) (Abcam, USA) primary antibodies in blocking solution at $4{ }^{\circ} \mathrm{C}$ overnight. After each of three rinses with PBS and blocking solution, the cells were incubated in blocking solution for $30 \mathrm{~min}$ at room temperature. After incubation of the cells in blocking solution with donkey anti-mouse IgG $\mathrm{Cy} 3$ conjugated secondary antibody (1:500) (Millipore, USA) for $2 \mathrm{~h}$ at room temperature in the dark, the cells were washed with PBS. Finally, the cells were counterstained with 4',6diamidino-2-phenylindole (DAPI) $(1 \mu \mathrm{g} / \mathrm{mL})$ (Invitrogen, Waltham, MA, USA), and images were acquired using a LSM 510 META Confocal Laser Scanning Microscope.

\section{Western blot analysis}

The cells were harvested and lysed at $4^{\circ} \mathrm{C}$ in radioimmunoprecipitation assay buffer and $100 \times$ protease inhibitor cocktail (Thermo Scientific, Waltham, MA, USA) for $1 \mathrm{~h}$. The lysate was centrifuged at 14,000 rpm, $30 \mathrm{~min}$ at $4^{\circ} \mathrm{C}$. The total protein concentration was quantified using a Pierce BCA protein assay kit (Thermo Scientific, USA). Cell extracts $(30 \mu \mathrm{g} /$ lane $)$ were separated by $12 \%$ polyacrylamide by SDS-polyacrylamide gel electrophoresis and transferred to polyvinylidene difluoride (PVDF) membranes using an iBlot transfer device (Invitrogen, USA). After blocking with 5\% skimmed milk in Trisbuffered saline containing $0.1 \%$ Tween 20 (TBST) for $1.5 \mathrm{~h}$, the membranes were incubated with anti-hrGFP $(1: 1,000$ dilution, Stratagene), anti-EGFP (1:1,000, Clontech), and anti- $\beta$ actin $(1: 1,000$, Cell Signaling) primary antibodies in TBST overnight at $4^{\circ} \mathrm{C}$. After washing with TBST, the membranes were incubated with rabbit horseradish peroxidase-conjugated secondary antibody $(1: 1,000)$ and mouse horseradish peroxidase-conjugated secondary antibody $(1: 1,000)$ (cell signaling) for $90 \mathrm{~min}$. Hybridization signals were detected using a Super Signal West Pico Chemiluminescent Substrate kit (Thermo Scientific, USA). Density of each protein was determined using the BIO-PROFIL Bio-1D ver.99.04 program. GFP expression was normalized by $\beta$-actin at each time point to monitor the NANOG promoters activity during differentiation into either adipocyte or neuronal lineages.

\section{RESULTS}

\section{Establishment of green fluorescent protein positive transgenic cell line}

To establish the transgenic cell lines of the GFP reporter system tracing expressions of bovine NANOG promoter ($420 /+181)$, mouse NANOG promoter $(-332 /+50)$ and human NANOG promoter $(-380 /+24)$, linear forms of cytomegalovirus (CMV) promoterless recombinant plasmids were integrated into genomic DNA of mouse R1 ESCs by electroporation. After neomycin positive selection, each positive transgenic ESC line was verified for GFP expression by confocal fluorescence microscopy. Bovine NANOG-GFP transgenic mouse ESC line expressed a strong level of GFP. Similarly, strong levels of GFP expression were observed in mouse and human NANOG transgenic cell lines (Figure 1).

\section{Down-regulation of bovine NANOG gene during neural differentiation for 16 days}

To determine whether NANOG-GFP transgene expression was down-regulated in mouse ESC differentiation, we examined NANOG-GFP transgene expression during differentiation toward neurons for 16 days without MEF and LIF. Down-regulation of bovine NANOG was detected by both fluorescence microscopy 

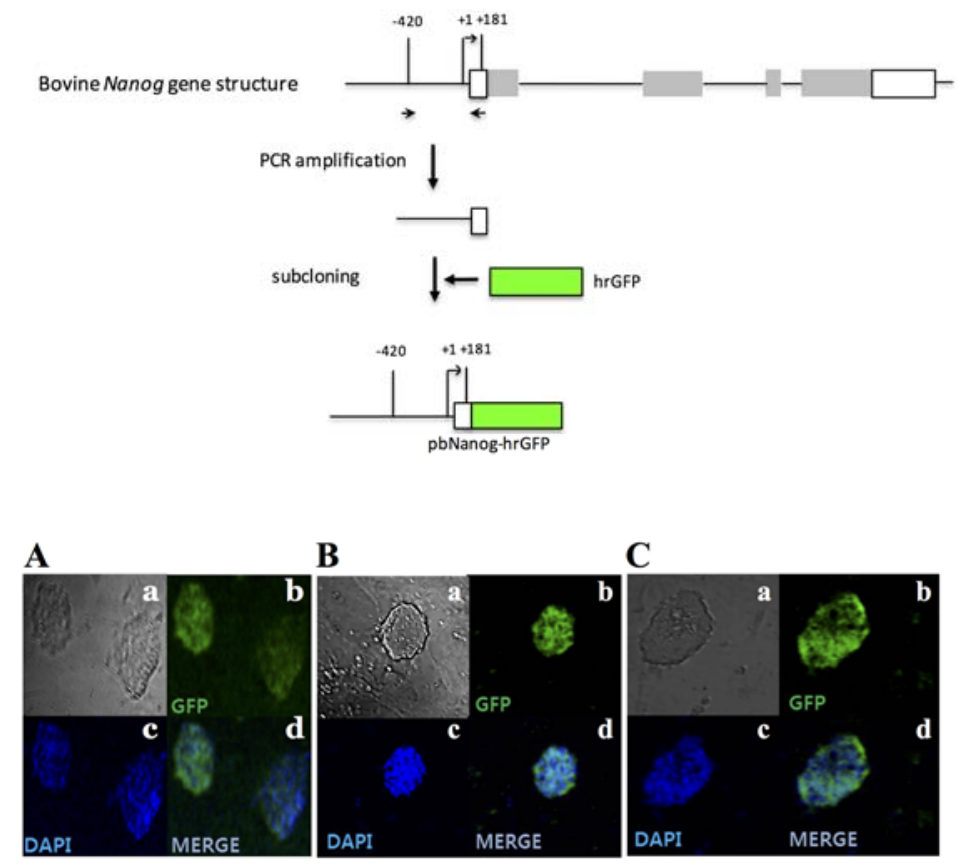

Figure 1. GFP positive transgenic cell lines. Fixed cells were detected under FITC and DAPI filters using a confocal microscope. (A) Bovine NANOG promoter-GFP transgenic mouse ESCs. (B) Mouse NANOG promoter-GFP transgenic mouse ESCs. (C) Human NANOG promoter-GFP transgenic mouse ESCs. Original magnification $\times 200$. (a) Bright field, (b) FITC, (c) DAPI, (d) merge FITC and DAPI.

(Figure 2A) and western blot analysis (Figure 2D). Neuron precursor marker NESTIN was detected from differentiated adhesive cells, but GFP expression was not detected on day
16. On day 8 after RA induction for neural differentiation, the level of GFP expression was decreased by approximately $66 \%$ compared with that of day 0 .

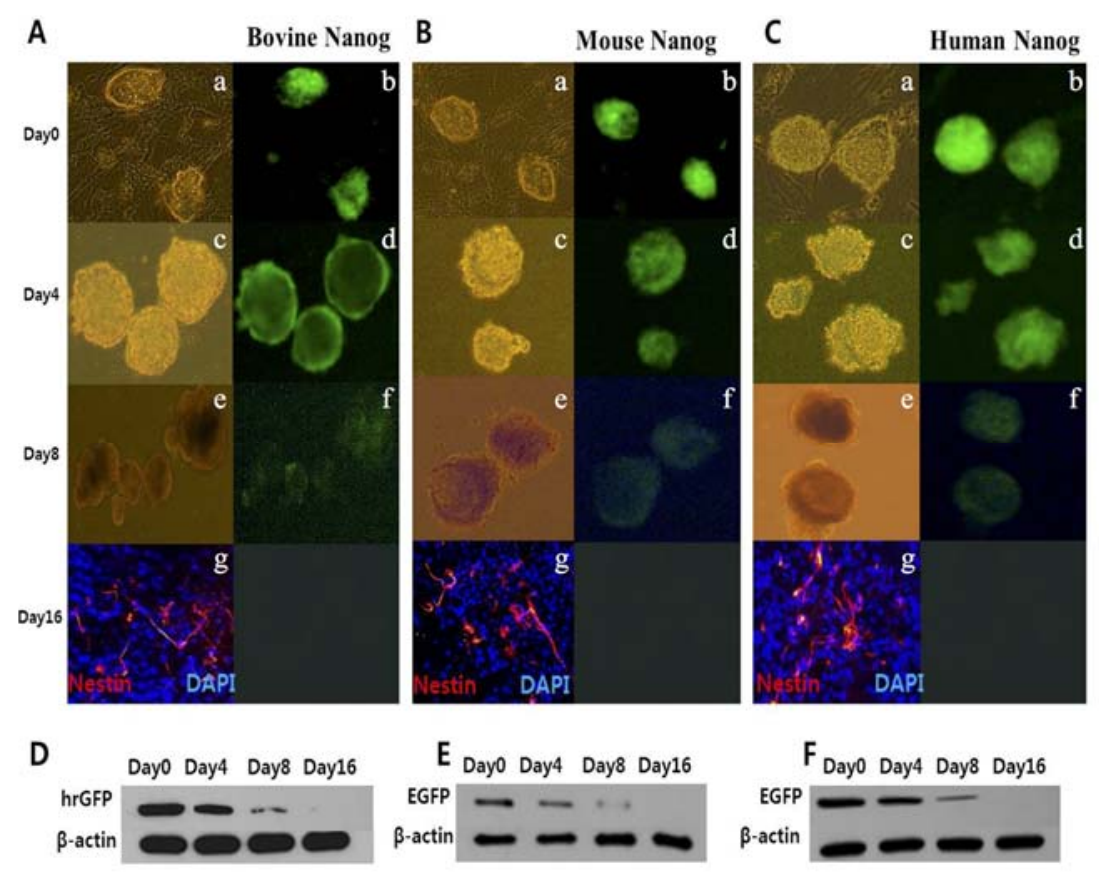

Figure 2. Down-regulation of GFP expression from GFP positive transgenic cell lines during neuron differentiation. (A-C) Morphological change and GFP expression of differentiated EB cells from bovine, mouse, and human NANOG transgenic ESC lines for 16 days of neural differentiation (original magnification $\times 100$ ), and immunofluorescence staining of differentiated adhesive cells on day 16 with NESTIN antibody (original magnification $\times 200$ ). (a,c,e) Bright field, (b,d,f) DAPI, g: merge Rodamine and DAPI. (D-F) Each GFP expression was detected by western blot on day $0,4,8$, and 16 . 
Table 1. Densities of proteins during neuron differentiation

\begin{tabular}{lccc}
\hline $\begin{array}{l}\text { Neuron } \\
\text { differentiation }\end{array}$ & $\begin{array}{c}\text { Bovine } N A N O G / \\
\beta \text {-Actin* }\end{array}$ & $\begin{array}{c}\text { Mouse } N A N O G / \\
\beta \text {-Actin* }\end{array}$ & $\begin{array}{c}\text { Human NANOG/ } \\
\beta \text {-Actin* }\end{array}$ \\
\hline Day 0 & 66.00 & 56.86 & 67.45 \\
& $(100 \%)$ & $(100 \%)$ & $(100 \%)$ \\
Day 4 & 53.63 & 42.21 & 53.24 \\
& $(81.26 \%)$ & $(74.24 \%)$ & $(78.93 \%)$ \\
Day 8 & 22.68 & 16.25 & 22.65 \\
& $(34.37 \%)$ & $(28.58 \%)$ & $(33.58 \%)$ \\
Day 16 & 0 & 0 & 0.00 \\
& $(0 \%)$ & $(0 \%)$ & $(0 \%)$ \\
\hline
\end{tabular}

* Expression of GFPs were normalized $\beta$-actin level. Protein bands were quantified as described in Methods and Materials. After quantification, the values of GFP bands were divided by those of $\beta$-actin.

Significantly down-regulated expression of mouse and human NANOG as reflected by GFP expression was also observed on day 8 of neuron differentiation by fluorescence microscopy (Figures 2B and 2C) and Western blot (Figures $2 \mathrm{E}$ and $2 \mathrm{~F}$ ). Mouse and human NANOG-GFP expression was decreased by approximately $71 \%$ and $66 \%$, respectively, on day 8 of neuron differentiation when compared with GFP expression on day 0 . The expression patterns of the bovine NANOG during neural differentiation were similar to those of mouse and human NANOG (Table 1).

\section{Down-regulation of bovine NANOG during adipocyte differentiation for 26 days}

To determine whether NANOG-GFP transgene expression was down- regulated during differentiation of another cell type, GFP expression was monitored during the differentiation of adipocytes for 26 days without MEF and LIF. Down-regulation of bovine NANOG was detected by both fluorescence microscopy (Figure 3A) and Western blot analysis (Figure 3D). Adipocyte marker C/EBP $\beta$ was detected from differentiated adhesive cells, but GFP expression was undetectable on day 26. As expected, bovine NANOG expression was gradually reduced during adipogenesis. In particular, 53\% decrease was observed on day 5 by induction of RA for 3 days on 2-day-old EB when compared with GFP expression on day 0. In addition, the expression of GFP driven by mouse and human NANOG promoter was decreased by approximately $53 \%$ and $58 \%$,
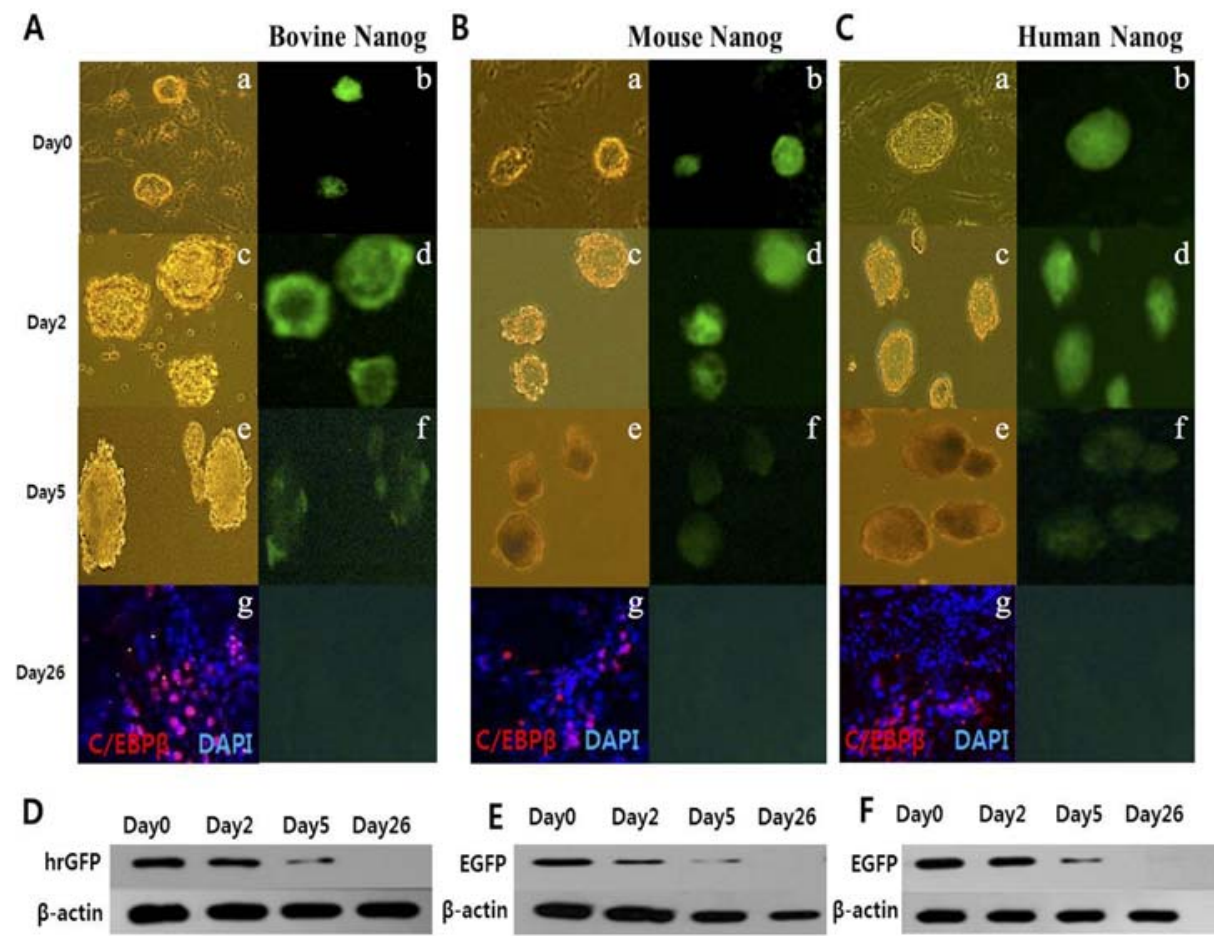

Figure 3. Down-regulation of GFP from GFP positive transgenic cell lines during adipocyte differentiation. (A-C) Morphological change and GFP expression of differentiated EB cells from bovine, mouse, and human NANOG transgenic ESC lines for 26 days of adipocyte differentiation (original magnification $\times 100$ ), and immunofluorescence staining of differentiated adhesive cells on day 26 with C/EBP $\beta$ antibody (original magnification $\times 200$ ). (D-F) Each GFP expression was detected by western blot on day 0, 2, 5, and 26. 
respectively, on day 5, compared with GFP expression on day 0 , as observed by both fluorescence microscopy (Figures 3B and 3C) and western blot (Figures 3E and 3F). The expression levels of GFP driven by the bovine NANOG promoter were comparable with those of GFP expression by both human and murine NANOG promoters (Table 2).

\section{DISCUSSION}

The critical features of ESCs provide an invaluable tool for studies related to developmental regulation, functional of genomics, and generation of gene manipulated animals (Hatano et al., 2005). NANOG is a crucial transcriptional factor for maintenance of pluripotency in mammalian embryos and ESCs (Vallier et al., 2009). NANOG expression is restricted to pluripotent cells and is downregulated upon differentiation (Mitsui et al., 2003). Therefore, understanding the action of NANOG expression in maintaining pluripotency and undifferentiated state of ESCs is important. Unfortunately, efforts made to establish validated bovine ESC lines have been fruitless (Chambers et al., 2003). Therefore, further improvements may be needed for studies on bovine development. In this study, we examined the function of bovine NANOG promoter using mouse ESCs. To determine whether the bovine NANOG gene promoter would have transcriptional activity in mouse ESCs, the construct of the 5'-flanking region of the bovine NANOG promoter $(-420 /+181)$ was transfected with hrGFP into mouse ESCs and neomycin resistant clones were selected and used for further study. Expression of bovine NANOG gene reflected by GFP expression in mouse ESCs was comparable with mouse and human NANOG gene promoter driven EGFP. This result demonstrates that the mechanism underlying transcriptional regulation might be conserved across the mammalian species. A previous study reported that the mouse and human NANOG promoter regions were capable of expressing GFP reporter construct in both mouse and human ESCs, and differentiation by chemical inducers such as retinoic acid decreased transcriptional activity of NANOG promoters. This phenomenon was also observed in another study, where treatment with $0.1 \mu \mathrm{M}$ RA for 3 days resulted in drastically reduced EGFP tagged mouse NANOG protein expression (Rodda et al., 2005). In the same study, FACS analysis indicated that mouse NANOG expression was reduced by $50 \%$ at 4 days of EB formation, and treatment with $0.1 \mu \mathrm{M}$ RA for 4 days resulted in $88 \%$ reduction of NANOG expression as well (Rodda et al., 2005).

As in previous studies (Kuroda et al., 2005; Rodda et al., 2005), in our study, GFP expression driven by mouse, human, and bovine NANOG promoters was down-regulated by $26 \%, 22 \%$, and $19 \%$, respectively, at 4 days of neural differentiation, and by $20 \%, 4 \%$, and $10 \%$, respectively, at 2 days of adipocyte differentiation. In addition, mouse, human, and bovine NANOG gene expression showed more rapid down-regulation at 4 days of $0.5 \mu \mathrm{M}$ RA induced neural differentiation $(46 \%, 45 \%$, and $47 \%$, respectively) and at 2 days of $0.1 \mu \mathrm{M}$ RA induced adipocyte differentiation $(34 \%, 54 \%$, and $46 \%$, respectively). Exposure of growing EBs to high-RA is known to markedly increase the rate of neural differentiation, whereas exposure to low-RA induces more mesodermal cells like adipocytes (Rohweddel et al., 1999). Higher concentrations of RA promote more rapid differentiation of ESCs, as indicated by the pattern of OCT4 expression, which was down-regulated more rapidly in EBs exposed to high-RA (Okada et al., 2004). In addition, OCT4 and NANOG expressions were directly repressed by GCNF during ESCs differentiation when induced by RA (Gu et al., 2005). GCNF, a transcriptional repressor, down-regulates target gene expression. Therefore, these results indicate that the mechanism for repression of NANOG expression in bovine NANOG during RA-induced differentiation may also be mediated by GCNF, however further study is warranted for investigation of molecular mechanisms for the conservation of transcriptional regulation of NANOG transcription during differentiation.

\section{Conclusion}

In this study, we report that the bovine NANOG 5'-

Table 2. Densities of proteins during adipocyte differentiation

\begin{tabular}{lccc}
\hline $\begin{array}{c}\text { Adipocyte } \\
\text { differentiation }\end{array}$ & $\begin{array}{c}\text { Bovine } N A N O G / \\
\text {-Actin* }\end{array}$ & $\begin{array}{c}\text { Mouse } N A N O G / \\
\beta \text {-Actin* }\end{array}$ & \multicolumn{2}{c}{ Human NANOG/ } \\
Day 0 & 59.53 & 55.97 & 67.79 \\
& $(100 \%)$ & $(100 \%)$ & $(100 \%)$ \\
Day 4 & 53.69 & 44.89 & 65.14 \\
& $(90.19 \%)$ & $(80.20 \%)$ & $(96.10 \%)$ \\
Day 8 & 27.80 & 26.18 & 28.57 \\
& $(46.70 \%)$ & $(46.77 \%)$ & $(42.15 \%)$ \\
Day 16 & 0 & 0 & 0 \\
& $(0 \%)$ & $(0 \%)$ & $(0 \%)$ \\
\hline
\end{tabular}

\footnotetext{
* Expression of GFPs were normalized $\beta$-actin level. Protein bands were quantified as described in Methods and Materials. After quantification, the
} values of GFP bands were divided by those of $\beta$-actin. 
flanking region from -420 to +181 has an essential role in NANOG transcriptional activity, which is important for maintenance of ESCs pluripotency. Therefore, this system has a potential impact on trace NANOG expression during bovine embryonic development and will contribute to establishment of bovine ESC lines in in vitro cultures using this construct as a potential marker for pluripotency.

\section{CONFLICT OF INTEREST}

We certify that there is no conflict of interest with any financial organization regarding the material discussed in the manuscript.

\section{ACKNOWLEDGMENTS}

This work was supported by a grant from the NextGeneration BioGreen 21 Program (Project No. PJ01109301), Rural Development Administration, Republic of Korea and Inha University Research Grant (INHA-50486).

\section{REFERENCES}

Boyer, L. A., T. I. Lee, M. F. Cole, S. E. Johnstone, S. S. Levine, J. P. Zucker, M. G. Guenther, R. M. Kumar, H. L. Murray, R. G. Jenner, D. K. Gifford, D. A. Melton, R. Jaenisch, and R. A. Young. 2005. Core transcriptional regulatory circuitry in human embryonic stem. Cell 122:947-956.

Buehr, M., S. Meek, K. Blair, J. Yang, J. Ure, J. Silva, R. McLay, J. Hall, Q. L. Ying, and A. Smith. 2008. Capture of authentic embryonic stem cells from rat blastocysts. Cell 135:1287-1298.

Chambers, I., D. Colby, M. Robertson, J. Nichols, S. Lee, S. Tweedie, and A. Smith. 2003. Functional expression cloning of Nanog, a pluripotency sustaining factor in embryonic stem cells. Cell 113:643-655.

Chickarmane, V., C. Troein, U. A. Nuber, H. M. Sauro, and C. Peterson. 2006. Transcriptional dynamics of the embryonic stem cell switch. PLoS Comput. Biol. 2:e123.

Doetschman, T., P. Williams, and N. Maeda. 1988. Establishment of hamster blastocyst-derived embryonic stem (ES) cells. Dev. Biol. 127:224-227.

Gerrard, L., D. Zhao, A. J. Clark, and W. Cui. 2005. Stably transfected human embryonic stem cell clones express OCT4specific green fluorescent protein and maintain self-renewal and pluripotency. Stem Cells 23:124-133.

Gu, P., D. LeMenuet, A. C. K. Chung, M. Mancini, D. A. Wheeler, and A. J. Cooney. 2005. Orphan nuclear receptor GCNF is required for the repression of pluripotency genes during retinoic acid-induced embryonic stem cell differentiation. Mol. Cell. Biol. 25:8507-8019.

Hatano, S.Y., M. Tada, H. Kimura, S. Yamaguchi, T. Kono, T. Nakano, H. Suemori, N. Nakatsuji, and T. Tada. 2005. Pluripotential competence of cells associated with Nanog activity. Mech. Dev. 122:67-79.

Hatoya, S., R. Torii, Y. Kondo, T. Okuno, K. Kobayashi, V. Wijewardana, N. Kawate, H. Tamada, T. Sawada, D. Kumagai,
K. Sugiura, and T. Inaba. 2006. Isolation and characterization of embryonic stemlike cells from canine blastocysts. Mol. Reprod. Dev. 73:298-305.

Hayes, B., S. R. Fagerlie, A. Ramakrishnan, S. Baran, M. Harkey, L. Graf, M. Bar, A. Bendoraite, M. Tewari, and B. Torok-Storb. 2008. Derivation, characterization, and in vitro differentiation of canine embryonic stem cells. Stem Cells 26:465-473.

Huang, B., T. Li, L. Alonso-Gonzalez, R. Gorre, S. Keatley, A. Green, P. Tumer, P. K. Kallingappa, V. Verma, and B. Oback. 2011. A virus-free poly-promoter vector induces pluripotency in quiescent bovine cells under chemically defined conditions of dual kinase inhibition. PLoS ONE 6:e24501.

Hamazaki, T., M. Oka, S. Yamanaka, and N. Terada. 2004. Aggregation of embryonic stem cells induces Nanog repression and primitive endoderm differentiation. J. Cell. Sci. 117:5681-5686.

Kim, M. J., A. Habiba, J. M. Doherty, J. C. Mills, R. W. Mercer, and J. E. Huettner. 2009. Regulation of mouse embryonic stem cell neural differentiation by retinoic acid. Dev. Biol. 328:456471.

Keefer, C. L., H. Baldassarre, R. Keyston, B. Wang, B. Bhatia, A. S. Bilodeau, J. F. Zhou, M. Leduc, B. R. Downey, A. Lazaris, and C. N. Karatzas. 2001. Generation of dwarf goat (Capra hircus) clones following nuclear transfer with transfected and nontransfected fetal fibroblasts and in vitro-matured oocytes. Biol. Reprod. 64:849-856.

Kuroda, T., M. Tada, H. Kubota, H. Kimura, S. Y. Hantano, H. Suemori, N. Nakatsuji, and T. Tada. 2005. Octamer and sox elements are required for transcriptional cis regulation of Nanog gene expression. Mol. Cell. Biol. 25:2475-2485.

Li, P., C. Tong, R. Mehrian-Shai, L. Jia, N. Wu, Y. Yan, R. E. Maxson, E. N. Schulze, H. Song, C. L. Hsieh, M. F. Pera, and Q. L. Ying. 2008. Germline competent embryonic stem cells derived from rat blastocysts. Cell 135:1299-1310.

Liu, N., M. Lu, X. Tian, and Z. Han. 2007. Molecular mechanisms involved in self-renewal and pluripotency of embryonic stem cells. J. Cell Physiol. 211:279-286.

Mitsui, K., Y. Tokuzawa, H. Itoh, K. Segawa, M. Murakami, K. Takahashi, M. Maruyama, M. Maeda, and S. Yamanaka. 2003. The homeoprotein Nanog is required for maintenance of pluripotency in mouse epiblast and ES cells. Cell 113:631-642.

Pain, B., M.E. Clark, M. Shen, H. Nakazawa, M. Sakurai, J. Samarut, and R. J. Etches. 1996. Long-term in vitro culture and characterization of avian embryonic stem cells with multiple morphogenetic potentialities. Development 122:23392348.

Okada, Y., T. Shimazaki, G. Sobue, and H. Okano. 2004. Retinoicacid-concentration-dependent acquisition of neural cell identity during in vitro differentiation of mouse embryonic stem cells. Dev. Biol. 275:124-142.

Okita, K. and S. Yamanaka. 2006. Intracellular signaling pathways regulating pluripotency of embryonic stem cells. Curr. Stem Cell Res. Ther. 1:103-111.

Rohweddel, J., K. Guan, and A. M. Wobus. 1999. Induction of cellular differentiation by retinoic acid in vitro. Cells Tissues Organs 165:190-202.

Rodda, D. J., J. L. Chew, L. H. Lim, Y. H. Loh, B. Wang, H. H. Ng, and P. Robson. 2005. Transcriptional Regulation of Nanog by 
$\mathrm{OCT}_{4}$ and SOX 2 . J. Biol. Chem. 280:24731-24737.

Suda, Y., M. Suzuki, Y. Ikawa, and S. Aizawa. 1987. Mouse embryonic stem cells exhibit indefinite proliferative potential. J. Cell. Physiol. 133:197-201.

Sukoyan, M. A., S. Y. Vatolin, A. N. Golubitsa, A. I. Zhelezova, L. A. Semenova, and O. L. Serov. 1993. Embryonic stem cells derived from morulae, inner cell mass, and blastocysts of mink: Comparisons of their pluripotencies. Mol. Reprod. Dev. 36:148-158.

Sumer, H., J. Liu, L. F. Malaver-Ortega, M. L. Lim, K. Khodadadi, and P. J. Verma. 2011. Nanog is a key factor for induction of pluripotency in bovine adult fibroblasts. J. Anim. Sci. 89:27082716.
Thomson, J. A., J. Kalishman, T. G. Golos, M. Durning, C. P. Harris, R. A. Becker, and J. P. Heam. 1995. Isolation of a primate embryonic stem cell line. Proc. Natl. Acad. Sci. USA 92:7844-7848.

Thomson, J. A., J. Itskovitz-Eldor, S. S. Shapiro, M. A.Waknitz, J. J. Swiergiel, V. S. Marshall, and J. M. Jones. 1998. Embryonic stem cell lines derived from human blastocysts. Science 282:1145-1147.

Vallier, L., S. Mendjan, S. Brown, Z. Chng, A. Teo, L. E. Smithers, M. W. Trotter, C. H. Cho, A. Martinez, P. Rugg-Gunn, G. Brons, and R. A. Pedersen. 2009. Activin/Nodal signaling maintains pluripotency by controlling Nanog expression. Development 136:1339-1349.

Wobus, A. M. and K. R. Boheler. 2005. Embryonic stem cells: Prospects for developmental biology and cell therapy. Physiol. Rev. 85:635-678. 